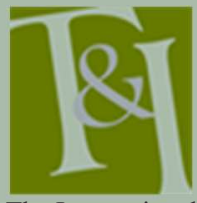

The International Journal for Translation \& Interpreting Research trans-int.org

\section{Fiction translation expectancy norms in Iran: a quantitative study of reception}

\author{
Masood Khoshsaligheh \\ Ferdowsi University of Mashhad, Iran \\ khoshsaligheh@um.ac.ir
}

\author{
Mohsen Kafi \\ Victoria University of Wellington, New Zealand \\ mohsen.kafi@vuw.ac.nz
}

\author{
Saeed Ameri \\ Ferdowsi University of Mashhad, Iran \\ s.ameri@mail.um.ac.ir
}

DOI : 10.12807/ti.112201.2020.a05

\begin{abstract}
Ever since the sociological turn in Translation Studies, readership has become a major consideration for translation researchers. An array of studies has focused on the reception of translated texts by professional (i.e. critics) and ordinary readers. In line with this view of readership, the current study adopts a quantitative approach to investigate the expectations of ordinary Iranian readers as to the features of a favourably received translation of foreign fiction into Persian. The authors validated the self-constructed Fiction Translation Expectancy Norms Scale and used it to elicit the opinions of a sample of 385 adult readers in Iran. Confirmatory factor analysis through structural equation modelling was employed to establish the construct validity of the results and empirically support a conceptual reclassification of the expectancy norms identified in an earlier study. The participants unanimously agreed that for a Persian translation of foreign fiction to be favourably received, it should be faithful to the author's tone and writing style. While most of the participants preferred a foreignising approach for the translation of culture-bound elements in the source text (ST), immersion in the translated text was found to be the most important dimension of foreign fiction translation for our sample of Iranian readers. These findings raise some doubts about the applicability of Venuti's model of foreignisation and domestication strategies to the literary translation scene in Iran.
\end{abstract}

Keywords: Translation expectations; reception studies; fiction translation; Iranian readership

\section{Introduction}

No matter how well a book is received in its original place of publication, it may or may not succeed in international markets. Instances of fiction and nonfiction doing great in one country and failing in others abound. This phenomenon may be partly attributed to poor translation quality or other translation-related issues, but the preferences and expectations of target-text readers are no less important. The focus on the target readership has been a recurring theme in Translation Studies, starting with Nida (1964), followed by Newmark (1981) and Venuti (1998), among others. In the existing research on translation, there have been frequent mentions of the reception of translated texts, as Chan (2016) notes. Notwithstanding such references, research has mainly focused on an 'implied reader', overlooking the experiences of 'real readers' (Suojanen, Koskinen, \& Tuominen, 2015). 
The present study aims to uncover the expectations of ordinary Iranian readers with regards to the features of a favourably received fiction translation into Persian, potentially contributing to the creation of a synergy between reception studies and the analysis of translations. After presenting a review of the literature and describing the theoretical foundation of the inquiry, the research questions will be nailed down, followed by an outline of the procedures of data collection and data analysis. The main findings will then be presented, complemented by a discussion of the findings and directions for further research.

\section{Literature review}

\subsection{Translation reception studies}

Marked by the sociological turn in early $21^{\text {st }}$ century (Wolf \& Fukari, 2007), translation research has moved beyond the mere analysis of translation products to the study of the human agents engaged in the translation process. While translator studies (Chesterman, 2009) has sparked off much interest among researchers, the audiences of translation products have received insufficient scholarly attention (Brems \& Ramos Pinto, 2013). Despite being a relatively new area of investigation, audiovisual translation research has successfully captured the responses and perceptions of some of its audiences (see Di Giovanni \& Gambier, 2018), as is the case with several studies on the audience perception and reception of audiovisual programs dubbed in Persian (Ameri \& Khoshsaligheh, 2018; Ameri, Khoshsaligheh, \& Khazaee Farid, 2018; Mehdizadkhani \& Khoshsaligheh, 2019) or subtilted into Persian (Khoshsaligheh, Ameri, Khajepour, \& Shokoohmand, 2019)

Literary translation reception has been examined using models borrowed from literary studies, where reception is synonymous with text analysis (Kruger \& Kruger, 2017). For Chan (2016), the target receiver represented in most models of translation is "the translator, whose interpretation, or reading, of the source text definitively shapes the translation" (p. 148). This is the premise of the contributions made by Nord (2000) and Sousa (2002), where translation reception is investigated using text analysis tools. Jääskeläinen (2012, p. 196) maintains that investigations of reception "still seem to be conspicuously absent from the entries of Translation Studies handbooks and encyclopaedias". This is probably because "moving from abstract theorizing about audiences to actual practice" has never been an easy task (Suojanen et al., 2015, p. 1). That may explain why translation scholars often talk about reception based on their own intuition and personal experiences, seldom providing enough empirical grounding or supporting evidence (Kruger, 2013).

Nonetheless, there are ample theoretical frameworks for defining and classifying reception studies within Translation Studies. Brems and Ramos Pinto (2013), for example, distinguish between two types of studies in terms of their models of audience:

1. Studies involving theoretical readers, where the concept of reception is approached from a social perspective, such as those adopting the polysystem theory.

2. Studies involving real readers, where the viewpoints of actual readers regarding translation products are taken into consideration.

The second group of studies investigate the readers' reactions to, attitudes towards, and assessment of translations. Suojanen et al. (2015) take Brems and Ramos Pinto's categorization a step further by dividing the research on 'actual readers' into four blocks, one of which deals with user attitudes towards translation products. These attitudes can be discerned through certain Social Sciences research instruments, including questionnaires and interviews (Suojanen et al., 2015). 
While empirical research on literary translation reception is relatively scarce, there are a few notable investigations. Kruger (2013) used eye-tracking technology to analyse how child and adult readers in South Africa respond to foreignised elements in picture books translated from English to Afrikaans. Along the same lines, Puurtinen (1994) examined the stylistic acceptability of the Finnish translation of children's literature by looking at user responses. In her doctoral dissertation on the reception of translated books in the United Kingdom, Campbell (2015) found that British readers are not concerned about whether a certain book has been translated into English, but they do consider the book's original language as a (de)motivating factor. Wang and Humblé (in press) examined readers' perception of a translated Chinese novel using reader reviews shared on Amazon. More recently, Pitkäsalo (2018) found that the focus group method could be effective for examining the readers' understanding and appreciation of comics.

The study conducted by Bijani, Khoshsaligheh, and Hashemi (2014) was an inquiry into the way readers' expectations of a given translation are shaped. The authors attempted to identify the main expectations of the regular readers of literary translations in Iran. Employing a mixed-methods research approach, Bijani et al. (2014) came up with a taxonomy of translation expectations which encompassed the following categories:

- Source cultural items: This category has to do with how the translator deals with culture-bound elements and the author's style and tone.

- $\quad$ Target text (TT) preface: The items of this category deal with the translator's preface, which often includes an ample discussion of translation difficulties, plot synopsis, and an outline of the main features of the story.

- Visualization: The items of this category look at how the translator clarifies the ambiguous parts of the ST and facilitates readers' immersion in the story.

- TT language: This category embraces such important issues as diversity of vocabulary, literary discourse, and sentence length.

- Authorial loyalty: Expectations regarding loyalty/faithfulness cover a range of issues including a discussion of the author's writing style in the preface and retaining that style throughout the translated text.

- Target culture: Respecting the conventions of the target culture and language, sense for sense translation, etc.

Due to their reliance on causal models for identifying the effects of a given translation product (Chesterman, 2007), reception studies are often considered as part of the sociological approach in Translation Studies. The reception of translation, or what is specifically known as translation effects, could be examined through three broad perspectives (Chesterman, 2007, pp. 179-180):

- Reactions: Reactions are behavioural in nature and concern the cognitive and emotional effects of a given translation on the reader. This is where Translation Studies goes hand in hand with cognitive sciences. Capturing 'viewer reaction' through advanced technologies such as eye-tracking and electroencephalography (EEG) has been the objective of a growing number of studies in subtitling reception (for example see Kruger, Doherty, Fox, \& de Lissa, 2018; Künzli \& Ehrensberger-Dow, 2011).

- Responses: Responses are more observable, as readers share their opinion about a given translation. This category encompasses professional reviews published in specialized literary journals or magazines and the opinions of ordinary readers shared online. 
- Repercussions: Repercussions are the effects of a translation which can potentially change the norms of the target culture or revolutionize the target language.

Inspired by the above-mentioned conceptual framework, Gambier (2018) proposed a reception framework in the context of audiovisual translation studies. His classification introduces ' 3 Rs', where the third R defines reception from an attitudinal point of view. Questions such as the audience's preferences and expectations can be investigated through this framework.

The next section elaborates on another core concept of the present study.

\subsection{Translation expectancy norms}

Translators are communication experts who tend to adhere to professional norms, which are themselves governed by product or expectancy norms. "In every culture, the nature of a good translation is determined by such norms, since "bad translations" are penalized in some way" (Pym, 2014, p. 71). By way of definition, readers determine the expectancy norms for a given type, say fiction translation (Chesterman, 2016 [1997]). Readers of translated texts probably have some expectations as to the "text-type and discourse conventions, style and register of the text, the appropriate degree of grammaticality, the statistical distribution of all types of text features, use of collocations, and lexical choice" (Chesterman, 2016 [1997], p. 62), to mention but a few. So far, the notion of 'expectation' has been mentioned sporadically in Translation Studies, but it has not turned into a flourishing area for empirical research (Risku, Pichler, \& Wieser, 2017). This could explain why studies on the reception of literary translation are only encountered sporadically in the literature.

\subsection{Fiction translation into Persian}

Iran, with its well-established tradition of literary translation, can be added to the list of countries enjoying a large volume of published translations. The development of literary translation in Iran reached a peak during the heyday of the Qajar dynasty in the 1850s, when the western novel genre was introduced into the Persian literary polysystem (see Even-Zohar, 2012; Karimi-Hakkak, 2009). The translation movement was part of a modernization project gaining momentum under Naser al-Din Shah Qajar's rule (reigned 1848-96). Before the reign of the Qajars, most translations into Persian were done from Arabic and Sanskrit. The Qajar period saw a significant rise in the number of books translated from English, French, Russian, and Turkish, mainly due to the political, administrative, and cultural needs of the Iranian society during that period (Naji-Nasrabadi, 2001).

Literary translation in post-revolution Iran is no less of a phenomenon. The authors did a quick search using a tool provided by Khane-ye Ketab-e Iran (Iran Book House $^{1}$ ) to see how many translated books are being published annually in Iran. Literature was chosen as the subject index and the one-year period between 20 March 2018 and 20 March 2019 was chosen as the 'date of publication'. The results revealed that roughly ten thousand translated books have been published in Iran under the literature category during this period. Dorosti (2018) reports on the best-selling books of nine major bookstores in Tehran during the early months of 2018, and almost half of these bookstores are owned by well-known publishers in Iran. According to this data, the Persian translation of Alain de Botton's The Consolations of Philosophy was the topselling book overall, followed closely by a Persian-language novel by Abbas

${ }^{1}$ A non-government organization which provides the bibliographic information of all the books published in Iran. 
Ma'roufi and The Forty Rules of Love written by Elif Shafak. Translated novels often outnumber Persian novels in best seller lists (Dorosti, 2018). While some Iranian publishers (e.g. Enghelab-e-Eslami and Soore-ye-Mehr) tend to focus on home-grown fiction, others (e.g. Thaleth, Ghoghnoos, and Cheshmeh) rely more on publishing translated books.

Iranian literary critics have looked at translation from different perspectives. Early critics were mainly concerned about the 'depurification' and 'degradation' of Persian as a result of low-quality translations. Some of the later critics have been more optimistic, arguing that translation has contributed a great deal to the simplification of Persian prose writing (e.g. Naji-Nasrabadi, 2001). Khazaee Farid (2001) discusses the idea of lafz-gerayi as a literary translation norm in Iran. Lafz-gerayi is a type of source-oriented translation approach through which the translator attempts to transfer the lexical, syntactical and stylistic features of the original text to the target text. It comes in two forms, namely extreme literal translation and moderate literal translation, only the second of which is recommended by Khazaee Farid for translating literature. Nevertheless, instances of the extreme form of lafz-gerayi can be found in many published translations in Iran (Khazaee Farid, 2001).

The reception of translation in Iran has often been discussed by 'influential recipients', including literary critics, publishers, and members of prize committees (Suojanen et al., 2015). The authors' inquiry is based on the premise that the reception of translated fiction by ordinary Iranian readers is still poorly understood.

\section{Research questions and method}

Given the previous discussion of literary translation reception, it seems clear that references to this topic are scarce and investigations are seldom empirical. The current study is an attempt to bring Iranian readers of translated fiction into the spotlight by answering the following questions:

1. What are the dimensions of a favourably received translation of foreign fiction into Persian for adult readers in Iran?

2. Is there a significant difference between the importance attached to the identified dimensions by Iranian readers?

3. What are the most and least important dimensions of a favourably received translation of foreign fiction for Iranian readers?

It should be noted that this participant-oriented study (Saldanha \& O'Brien, 2013) only considers prose fiction written for adults which has been translated into Persian, irrespective of its language of origin. It uses confirmatory factor analysis (CFA) through structural equation modelling (SEM). CFA is an advanced statistical procedure - a form of factor analysis -which is currently employed to determine the construct validity of survey data in the social sciences. It tests whether the collected data fit the measurement model initially hypothesized by the researchers (Schumacker \& Lomax, 2004).

\subsection{Sample}

Overall, 385 Iranian readers of translated fiction ( $80 \%$ female; $20 \%$ male) participated in this study by filling out a self-report closed-ended questionnaire. The apparent gender imbalance among the participants reflects the current dynamics of Iranian fiction readership. In fact, observations of the present clientele of a few bookstores and book cafes in Mashhad, Iran, supported the idea that women are the ones who are keeping the Iranian literary publishing 
industry afloat ${ }^{2}$. The available literature suggests that such a gender imbalance in fiction readership is the norm rather than the exception (for example see Yankelovich \& White, 1978; McEwan, 2005). Due to the disproportionate representation of female and male participants, gender was not treated as a separate variable of the study.

One of the main inclusion criteria was for the potential participants to consider themselves regular readers of translated fiction. More specifically, the potential participants had to have read at least three translated fiction books in the preceding 12 months in order to be included in the sample. There was, however, no restrictions regarding the participants' gender, age, or level of education. All participants had Persian as their native language. The sample of the study was selected from Khorasan Razavi Province in northeast Iran. Therefore, the authors make no claims about the generalizability of the findings to the entire Iranian society.

\subsection{Data collection instrument}

A previously designed 48-item questionnaire (Bijani et al., 2014) used for a similar purpose but with a more limited target population was reviewed by three Iranian translation scholars in an attempt to establish its content validity. The items of the original questionnaire were selected from a pool of expectations mentioned by a sample of Iranian readers during several focus group sessions. Bijani et al. (2014) validated the questionnaire in the Iranian context. As a result of the review process, some of the items were rewritten for further clarification, but the number of items remained the same. Our exchanges with the reviewers at the content validation stage led to the decision to conceptually re-categorize the items of the original questionnaire.

The new version of the questionnaire (Appendix A), which we call the Fiction Translation Expectancy Norms Scale, consists of three sections: a short introductory text, demographic information, and the main items. The items were intended to be rated by the participants on a five-point scale from 1 (not important at all) to 5 (very important).

To begin the data collection process, the authors approached the managers of two public libraries and eight major bookstores in Mashhad to ask for their consent to distribute the questionnaire among their patrons and customers. Both libraries and six of the bookstores provided us with written consent. Subsequently, two of the researchers showed up at the libraries and bookstores and asked some of the visitors if they were interested to participate in a survey about translated books. After making sure the potential participants met the three-books-a-year criterion, the researchers clearly explained the purpose of the research and how the questionnaire was to be completed.

\section{Results}

The sample of this study consisted of 385 regular readers of translated fiction in Mashhad, Iran. Table 1 below shows the data pertaining to the participants' gender and highest completed level of education.

Table 1. The demographics of survey participants

\begin{tabular}{llcrrrr}
\hline & & \multicolumn{2}{c}{ Education } & \multicolumn{2}{c}{ Total } \\
& & High school & BA & MA & PhD & \\
\hline \multirow{2}{*}{ Gender } & Female & 35 & 145 & 111 & 17 & 308 \\
\cline { 2 - 7 } & Male & 5 & 42 & 26 & 4 & 77 \\
\hline \multirow{2}{*}{ Total } & 40 & 187 & 137 & 21 & 385 \\
\hline
\end{tabular}

${ }^{2}$ This might be internationally the case if one looks at the clientele of bookshops and libraries. 
4.1 Dimensions of favourably received foreign fiction translation into Persian Several statistical procedures were conducted to address the first research question - that is, to confirm the new model of categorization. Six of the items of the original questionnaire did not conceptually fit into any of the newly defined categories, which led to their omission. Table 2 displays the final conceptual categorization and the labels chosen for each category, which represents the common theme of the items within that category.

Table 2. Achieved categories of survey items

\begin{tabular}{lll}
\hline Category & Label & Item Number* \\
\hline Factor 1 & Faithfulness & $01-14-15-30-37-47$ \\
\hline Factor 2 & Immersion & $06-26-29-42$ \\
\hline Factor 3 & Footnoting & $31-34-38-48$ \\
\hline Factor 4 & Paratext & $07-20-21-22-24-33-35-36-40-43$ \\
\hline Factor 5 & Translation Language & $4-9-12-16-27-32-39-45-44$ \\
\hline Factor 6 & Translation Strategies & $8-13-25-28$ \\
\hline Factor 7 & Readership & $2-11-19-18-46$ \\
\hline Excluded survey items & $3-5-10-17-23-41$ \\
\hline
\end{tabular}

The first category, Faithfulness, was mainly related to issues of loyalty and faithfulness to the original text, including the retention of the author's writing style and capturing the stylistic features of the ST. Immersion was the label chosen for the second factor, which considers how a reader is engaged with and immersed in a translated text, for example through strong visualization by the translator. The third factor (Footnoting) is concerned with how foreign expressions, culture-bound elements, and proper names are dealt with in the text, footnotes or endnotes (Aixelá, 1996). The label selected for the fourth factor was Paratext, which mainly deals with the elements constituting the preface to the translation. Translation Language and Translation Strategies were the fifth and sixth factors, respectively. The former is concerned with the language of the target text, including the clarity of language, dominant register, and style, while the latter considers the general strategies adopted by the translator, including word-for-word or sense-for-sense translation, among others. Finally, the seventh factor was labelled Readership, simply because it covers items such as the readers' sense of enjoyment from reading the translation, and the translator's consideration of the readers' cultural background and respect for the norms of the target language and culture.

Table 3 displays the correlations between the whole scale and each of the seven categories. The results indicate a meaningful correlation among the various dimensions. They also show that 'Paratext' has the highest $(r=.80, p<$ $.001)$ and 'Faithfulness' the lowest $(r=.36, p<.001)$ correlation with the overall fiction translation norms.

To test and confirm the conceptual model and investigate the generalizability of the survey findings, confirmatory factor analysis (CFA) was run through structural equation modelling (SEM) on IBM SPSS Amos (Version 21). The model alongside all the factor loadings are displayed in Figure 1 which graphically illustrates the relationships among the sub-constructs/factors in the hypothesized model. The association between the sub-factors of the proposed model was analysed based on CFA results. As shown in Figure 1, the seven subconstructs of the scale were confirmed: Faithfulness, Immersion, Footnoting, Paratext, Translation Language, Translation Strategies, and Readership. 
Table 3. Correlations between the subscales of the Fiction Translation Expectancy Norms Scale

\begin{tabular}{lcccccccc}
\hline & $\mathbf{1}$ & $\mathbf{2}$ & $\mathbf{3}$ & $\mathbf{4}$ & $\mathbf{5}$ & $\mathbf{6}$ & $\mathbf{7}$ & $\mathbf{8}$ \\
\hline 1. Faithfulness & 1.00 & & & & & & & \\
\hline 2. Immersion & $.26^{* *}$ & 1.00 & & & & & & \\
\hline 3. Footnoting & $.29^{* *}$ & $.16^{* *}$ & 1.00 & & & & & \\
\hline 4. Paratext & $.11^{*}$ & $.28^{* *}$ & $.40^{* *}$ & 1.00 & & & & \\
\hline 5. Translation Language & $.21^{* *}$ & $.46^{* *}$ & $.28^{* *}$ & $.44^{* *}$ & 1.00 & & & \\
\hline 6. Translation Strategies & $.20^{* *}$ & $.42^{* *}$ & $.24^{*}$ & $.38^{* *}$ & $.39^{* *}$ & 1.00 & & \\
\hline 7. Readership & .07 & $.22^{* *}$ & $.14^{* *}$ & $.39^{* *}$ & $.42^{* *}$ & $.39^{*}$ & 1.00 & \\
\hline 8 Overall & $.36^{* *}$ & $.56^{* *}$ & $.55^{* *}$ & $.80^{* *}$ & $.76^{* *}$ & $.62^{* *}$ & $.59^{* *}$ & 1.00 \\
\hline "* Correlation is significant at the 0.01 level (2-tailed) & & & & & & \\
\hline Correlation is significant at the 0.05 level (2-tailed) & & & & & & & \\
\hline
\end{tabular}

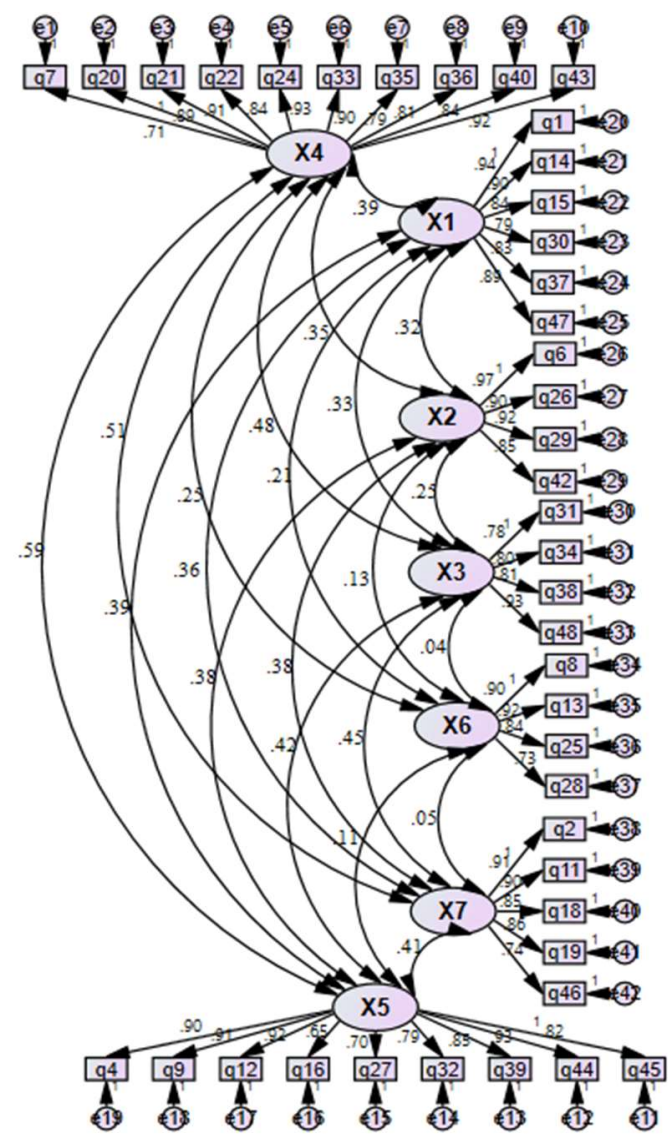

Figure 1. CFA model of the Fiction Translation Expectancy Norms Scale Key: $\mathrm{x} 1=$ Faithfulness, $\mathrm{x} 2=$ =Immersion, $\mathrm{x} 3=$ Footnoting, $\mathrm{x} 4=$ Paratext, $\mathrm{x} 5=$ Translation Language, $\mathrm{x} 6=$ Translation Strategies, $\mathrm{x} 7=$ Readership

To check the model fit, the goodness of fit indices were reviewed (Table 4). In this study, $\chi^{2} / \mathrm{df}$, GFI (Goodness of Fit Index), NFI (Normed Fit Index), CFI (Comparative Fit Index), and RMSEA (Root Mean Square Error of Approximation) were employed. To have a well-fit model, $\chi^{2} / \mathrm{df}$ should be less than 3 (Ullman, 2001), GFI, CFI, and NFI should be above .90, and RMSEA should be less than .06 (Schumacker \& Lomax, 2004). 
Table 4. Goodness of fit indices for the CFA model of categorization

\begin{tabular}{lccccccc}
\hline Indices & $X^{2}$ & $d f$ & $X 2 / d f$ & GFI & NFI & CFI & RMSEA \\
\hline Acceptable fit & & & $<3$ & $>.90$ & $>.90$ & $>.90$ & $<.06$ \\
\hline Model & 2281.71 & 798 & 2.85 & .93 & .94 & .91 & .058 \\
\hline
\end{tabular}

The results signalled no need for modification, since all the goodness of fit indices were within the acceptable range. In other words, the scale enjoyed perfect validity.

Cronbach's alpha values are often used to establish the reliability of questionnaire data. A reliability coefficient of .70 or higher is considered 'acceptable' in most social and psychological research contexts (Field, 2009). The alpha coefficient obtained for the whole scale (.85) suggests that the items enjoy a high level of internal consistency.

\subsection{Do the dimensions differ in importance?}

In response to the second research question, repeated analysis of variance (ANOVA) measures were employed to test if the participants' perceptions of the importance of the expectation categories were significantly different pairwise.

Mauchly's test indicated that the assumption of sphericity had been violated, $\chi^{2}(20)=267.59, p<.05$; therefore, Greenhouse-Geisser correction was used and the results of multivariate tests were reported $(\varepsilon=0.81)$. The ANOVA test results revealed significant differences in the perceptions of the participants about the types of expectations, $F(4.85,1847.32)=141.60, p<.05$; also, the effect size was large (partial eta squared $=.27$ ). Following the establishment of significant differences in the mean scores of the seven expectation categories, the Bonferroni post hoc test for multiple pair-wise comparisons indicated significant differences $(p<.05)$ among all the subsets except for subsets 1 vs. 3,1 vs. 5 and 3 vs. 5 .

\subsection{The most important dimensions}

Given the significant difference among the categories from the viewpoint of the participants, the seven dimensions of a favourably received translation of foreign fiction into Persian were ranked in a decreasing order of importance according to the obtained mean scores (Table 5).

Table 5. Ranking of the categories in a decreasing order of importance

\begin{tabular}{lccc}
\hline Category & Rank & Mean Score & Standard Deviation \\
\hline Immersion & 1 & 4.16 & .54 \\
\hline Faithfulness & 2 & 3.94 & .53 \\
\hline Footnoting & 3 & 3.92 & .74 \\
\hline Translation Language & 4 & 3.85 & .48 \\
\hline Translation Strategies & 5 & 3.69 & .64 \\
\hline Readership & 6 & 3.45 & .72 \\
\hline Paratext & 7 & 3.21 & .69 \\
\hline Overall & & 3.70 & .39 \\
\hline
\end{tabular}

Reviewing the results presented in Table 5 helps address the final question of the study, which aimed to determine the most and least important dimensions of a favourably received translation of foreign fiction into Persian for Iranian readers. None of the dimensions received a mean score close to 5, which implies that none of the categories were considered 'very important' by the participants. Nonetheless, the Immersion category received a mean score well above 4, which represented an 'important norm' on the scale. This score is the highest of all the categories, so immersion is the most important dimension of foreign fiction translation for the Iranian sample of the study. Faithfulness and Footnoting 
received mean scores just above and just below 4 , and were the second and third most important dimensions, respectively. According to the data presented in Table 5, Translation Language was the fourth most important dimension with a mean score close to 4 .

The remaining three categories, namely Translation Strategies, Readership, and Paratext, all received scores of approximately 3.5, which signifies a degree of uncertainty on the part of participants in terms of their importance. The large values of standard deviation (closer to 1.00) for these three dimensions point to a dispersed distribution of responses on either ends of the importance scale.

At this stage, an item-by-item check could provide a better understating of the readers' expectations of a fiction translation into Persian (for the full list of 48 items, please consult Appendix A). Three of the constituting items of the Faithfulness category were positively rated by the respondents, namely 'placing importance on the fidelity principle in retaining the style of the ST' $(M=4.37)$, 'keeping the author's style unless for a solid reason' $(M=4.09)$, and 'transferring the names of cultural ceremonies, foods, and customs of the ST to the TT without any changes' $(M=4.05)$. The analysis of the mean scores obtained for the second category (Immersion) suggested a strong agreement on three of its items: 'transmitting the real spirit of the ST to the target reader' ( $M$ $=4.56)$, 'helping the readers become immersed in the story' $(M=4.47)$, and 'enabling effective visualization of the events of the story' $(M=4.29)$. Unlike the previous categories, only one item of the Footnoting category obtained a mean score of over four $(M=4.09)$ : 'Providing explanations for unfamiliar culture-bound elements in the footnotes'. Quite surprisingly, most of the respondents were undecided about the items in the Paratext category, except for one item which was 'of little importance' to most of the participants: 'describing the difficulties of translating the text' $(M=2.55)$.

When it comes to Translation Language, the mean scores of four of the items averaged above four: 'Ensuring the readability of the TT for the target readers' $(M=4.50)$, 'giving due consideration to the correct usage of Persian grammar' $(M=4.34)$, 'Using a clear and rational language in the TT' $(M=4.24)$, and 'Consistency in the writing style of the TT' $(M=4.05)$. The respondents' mean ratings of the Translation Strategies dimension show some uncertainty, aside from the first item of this category which received a mean score just below 4: 'avoiding word-for-word translation' $(M=3.99)$. The other items of this category were 'retaining the distinguished features of the source culture represented in the ST' $(M=3.80)$, 'disambiguating the ST' $(M=3.58)$, and 'literal translation of the sensitive/important parts of the ST' $(M=3.36)$. The participants unanimously agreed on only one item of the Readership dimension, which was 'Foregrounding the aesthetic features of the text for the enjoyment of readers' $(M=4.04)$. Also, one item of the Readership category was deemed to be of little importance to the respondents: 'translating the works of wellknown international authors' $(M=2.55)$. Overall, the participants appeared to strongly agree on the importance of one-third of the questionnaire items $(n=13)$, leaving the rest of the items open to debate.

\section{Discussion}

The present study intended to investigate the expectations of adult Iranian readers as to the textual, paratextual and extratextual features of a favourably received foreign fiction translation into Persian. The investigation yielded several important findings which could potentially contribute to the existing knowledge on literary translation reception in Iran. Having applied a unique research method, we found that the readership expectations could be divided into seven categories, namely Faithfulness, Immersion, Footnoting, Paratext, 
Translation Language, Translation Strategies, and Readership. None of the dimensions were rated either 'very important' or 'not important at all'. About one-third of the items were rated 'important', less than five percent were 'of little importance', and the rest of the items remained undecided. The specificity of some of the questionnaire items and the lack of a strong public discourse on the process and practice of literary translation in Iran could be potential reasons for the participants' indecisiveness over more than half of the items. The other reason could be ascribed to the likely variation of readers' attitudes from one translation situation to another, or even from one genre to another.

The participants appeared to find three of the dimensions 'important' for a Persian translation of foreign fiction to be favourably received. The most important dimension was immersion, which concerns the readers' engagement with the translated text, and how the translation itself can facilitate or impede immersion. The second and third most important dimensions were faithfulness and footnoting, respectively. The co-appearance of immersion, footnoting, and faithfulness as the most important aspects of a fiction translation into Persian is somewhat surprising. Immersion, as mentioned above, could be understood as the extent to which readers get "immersed or absorbed in the fictional reality, to the extent that they become less aware of their immediate surroundings" (Kruger, Sanfel, Doherty, \& Ibrahim, 2016, p. 178). Footnoting may hamper the experiences of readers of the translation as it diverts their attention away from the main text, possibly resulting in decreased immersion. However, we do not know what happens in reality, as psychological immersion has not been examined in literary translation (Kruger \& Kruger, 2017, p. 78) and there is no empirical evidence to show if there is any negative correlation between immersion and footnoting; therefore, this claim should be substantiated through robust empirical experiments in the future. Readers' comprehension and understating should also be accounted for, as footnoting - provided that it offers necessary information - can lead to a better understating of the story, and consequently, a higher immersion in the story world. Aside from this, the relevant literature (e.g. Khazaee Farid, 2001; Moshtaqmehr, 2000) suggests that foreignising translations or the extreme form of lafz-gerayi are broadly more prevalent in Persian than in English, and therefore perceived as less of an obstacle to immersion. Additionally, the readers' criteria, as brought to light by the questionnaire, may not be perfectly coherent. Therefore, any attempt to make more general conclusions based on this data must be supported by further empirical evidence.

The Iranian readers' perceptions of fiction translation into Persian should be analysed in light of the position of translated fiction in the Iranian literary polysystem (see Even-Zohar, 1979; Khazaee Farid \& Ashrafi, 2012) and the social status of Iranian translators (Kafi, Khoshsaligheh, \& Hashemi, 2018). Khazaee Farid and Ashrafi (2012) draw on the number of original and translated novels published in Iran during the first decade of the $21^{\text {st }}$ century to determine the position of translated literature in the Iranian literary polysystem. They conclude that translated literature has retained its position at the centre of the polysystem, showing no signs of moving to the periphery.

A review of the items rated 'important' by the participants indicates that 'faithfulness to the author's original writing style', 'an offer of a deeper immersion in the translation', 'a literal translation of proverbs in the footnote', and 'translation of the author's introduction and biography in the preface' supposedly make a translation more enjoyable for Iranian readers. The first, third, and fourth items mentioned above are often associated with a foreignising translation approach, which makes the translator more visible. In this case, the participants' viewpoint is in accordance with that of Khazaee Farid (2015) who considers faithfulness in terms of content and style as one of the main criteria for a "good" translation in the Iranian context. Campbell (2015) also found that 
although readers in the United Kingdom universally prefer fluency, they do like to occasionally encounter ST culture-specific concepts in the translated text.

The items which were 'of little importance' to the participants included 'describing the difficulties of translating the text' and 'translating the works of well-known international authors', among others. The findings with regards to the former item can be justified by the participants' willingness to be immersed in the story. The description of translation difficulties may create prejudgments about the difficulty level of the book and therefore impede immersion. A rather unexpected finding is that Iranian readers of translated fiction do not seem to find footnoting as an impediment to immersion. This is in sharp contrast with how most of the publishers of fiction translation in the English-speaking world view footnotes. From their point of view, footnotes take the reader out of the story world. On the bright side, however, footnotes may help the readers become more immersed in the translation by offering necessary information, thereby facilitating their understating of the story. Wang and Humble (in press), for example, argue that "helpful footnotes" often improve the readability of the prose and assist the readers in perceiving the peculiarities of the original. Empirical evidence can objectively substantiate or reject such opinions. One potential reason for Iranian readers' positive reception of footnotes in translated fiction is a common perception of the translator's role in Iran: explainer rather than reflexive analyst (Bryant, 2002).

The apparent indifference of the participants to the status of international writers whose works are translated into Persian may indicate not only that Iranian readers are curious about lesser-known writers, but also that they would like to be able to resist market censorship. According to Clawson (1997), both publishers and chain booksellers increasingly look for books which can potentially produce enough profit to cover the publication and circulation costs. As a result, it is extremely difficult for lesser-known writers to have their novels published and promoted.

For the Iranian readers participating in this study, a 'good' or 'successful' Persian translation of foreign fiction is one that is complete and faithful to the original. This finding is consistent with the faithfulness criterion advocated by Iranian translation critics (Khazaee Farid, 2015). Furthermore, it could potentially reflect the readers' longing for access to uncensored translated books. One cannot overlook the impact of state censorship on the possible incompleteness of fiction books translated into Persian, because the Ministry of Culture and Islamic Guidance acts as a watchdog agency in Iran, controlling and monitoring the publication of cultural products, including translated books and films.

\section{Concluding remarks}

As with most studies, the current study is subject to several (de)limitations. Although a large sample of Iranian readers was surveyed for this research, the recruitment of larger samples based on random selection might have enhanced the generalizability of the findings. Future studies on the topic could survey samples of Iranian participants from diverse social, cultural and educational backgrounds. Also, in-depth interviews with purposively selected samples of readers would allow for the cross-examination of quantitative findings, providing more insights into the preferences and attitudes of Iranian readers. Running experimental studies using state of the art technologies such as eyetracking, EEG, and heart rate monitoring could be another line for future research (for example see Walker, 2019), potentially enriching our understanding of translation reception at a cognitive level.

By offering in-depth authentic data about the preferences and expectations of the readers of literary translations, reception studies could contribute to 
bridging the gap between translation theory and practice. While this group of studies mainly investigate the reception of translation products by target readers, their findings can be used to inform literary translator education, and thus have an impact on the translation process. The publishing industry too can use the findings of reception studies to fulfill the expectations of the mainstream readership, ultimately increasing its own long-term profits.

\section{References}

Aixelá, J. F. (1996). Culture-specific items in translation. In R. Alvarez \& M. CarmenAfrica Vidal (Eds.), Translation, power, subversion (pp. 52-78). Clevedon: Multilingual Matters.

Ameri, S., \& Khoshsaligheh, M. (2018). Exploring the attitudes and expectations of Iranian audiences in terms of professional dubbing into Persian. Hermes, 57, 175193.

Ameri, S., Khoshsaligheh, M., \& Khazaee Farid, A. (2018). The reception of Persian dubbing: a survey on preferences and perception of quality standards in Iran. Perspectives: Studies in Translation Theory and Practice, 26(3), 435-451. doi:10.1080/0907676X.2017.1359323

Bijani, S., Khoshsaligheh, M., \& Hashemi, M. R. (2014). Categorization of the fiction translation expectancy norms to Iranian undergraduate readership. Asia Pacific Translation and Intercultural Studies, 1(3), 210-221. doi:10.1080/23307706. 2014.956982

Brems, E., \& Ramos Pinto, S. (2013). Reception and translation. In Y. Gambier \& L. van Doorslaer (Eds.), Handbook of translation studies (pp. 142-147). Amsterdam: John Benjamins.

Bryant, C. G. (2002). George Soros's theory of reflexivity: a comparison with the theories of Giddens and Beck and a consideration of its practical value. Economy and Society, 31(1), 112-131. doi: 10.1080/03085140120109277

Campbell, C. (2015). Translation and the reader: A survey of British book group members' attitudes towards translation. (Unpublished doctoral dissertation, University of Edinburgh). Retrieved from: https://era.ed.ac.uk/handle/1842/20948

Chan, L. T. H. (2016). Reader response and reception theory. In C. V. Angelelli \& B. J. Baer (Eds.), Researching translation and interpreting (pp. 146-154). Abingdon, England: Routledge.

Chesterman, A. (2007). Bridge concepts in translation sociology. In M. Wolf \& A. Fukari (Eds.), Constructing a sociology of translation (pp. 171-183). Amsterdam: John Benjamins.

Chesterman, A. (2009). The name and nature of translator studies. Hermes, 42, 13-22.

Chesterman, A. (2016 [1997]). Memes of translation: The spread of ideas in translation theory (Revised ed.). Amsterdam: John Benjamins.

Clawson, D. (1997). Market censorship--books under attack. Contemporary Sociology, 26(5), VII-VIII. Retrieved from https://search.proquest.com/docview/ 233588770 ?accountid=14782

Di Giovanni, E., \& Gambier, Y. (Eds.). (2018). Reception studies and audiovisual translation. Amsterdam: John Benjamins.

Dorosti, M. (2018, April 25). Bazar-e Ketab-e Iran dar Taskhir-e Nevisande-ye Suisi/Mizan-e Foroosh-e Ketab dar Ayyam-e Pish az Namayeshgah [Iran's Book Market Dominated by a Swiss Writer/Book Sales in the Days Leading to Tehran Book Fair]. Farhangnevis. Retrieved from http:/farhangnevis.ir/fa/news/ID/ 42850/ categoryId/4/

Even-Zohar, I. (1979). Polysystem theory. Poetics today, 1(1/2), 287-310.

Even-Zohar, I. (2012). The position of translated literature within the literary polysystem. In L. Venuti (Ed.), The translation studies reader (3rd ed., pp. 162167). Abingdon, England: Routledge.

Field, A. (2009). Discovering statistics using SPSS (3rd ed.). Dubai, The United Arab Emirates: SAGE.

Gambier, Y. (2018). Translation studies, audiovisual translation and reception. In E. Di Giovanni \& Y. Gambier (Eds.), Reception studies and audiovisual translation (pp. 43-66). Amsterdam, The Netherlands: John Benjamins. 
Jääskeläinen, R. (2012). Translation pychology. In R. Jääskeläinen (Ed.), Handbook of translation studies (Vol. 3, pp. 191-197). Amsterdam: John Benjamins.

Kafi, M., Khoshsaligheh, M., \& Hashemi, M. R. (2018). Translation profession in Iran: current challenges and future prospects. The Translator, 24(1), 89-103. doi:10.1080/13556509.2017.1297693

Karimi-Hakkak, A. (2009). Persian tradition. In M. Baker \& G. Saldahna (Eds.), Routledge encyclopedia of translation studies (pp. 493-501). Abingdon, England: Routledge.

Khazaee Farid, A. (2001). Literary translation in Iran: The Status Quo. In A. Khazaee Farid (Ed.), Proceedings of the First Conference on Literary Translation in Iran (pp. 5-11). Mashhad, Iran: Ferdowsi University of Mashhad Press.

Khazaee Farid, A. (2015). Tarjome-ye Khub che Tarjomeyi Ast; Do shive-ye naghd-e tarjome dar Iran [What translation is a good translation; Two approaches for translation criticism in Iran]. BBC Persian. Retrieved from http://www.bbc.com/ persian/arts/2015/06/150606 141 book translation khazaeefar_summary

Khazaee Farid, A., \& Ashrafi, N. (2012). Negahi tosifi be vazi'yat-e tarjome va ta'lif-e adabi dar nezam-e chandgane-ye adabi-ye Iran dar dahe-ye 1380 [A descriptive analysis of the status of original and translated literature in the literary polysystem of Iran in the first decade of the $21^{\text {st }}$ century]. Language and Translation Studies, 45(1), 19-41.

Khoshsaligheh, M., Ameri, S., Khajepour, B., \& Shokoohmand, F. (2019). Amateur subtitling in a dubbing country: The reception of Iranian audience. Observatorio, 13(3), 71-94.

Kruger, H. (2013). Child and adult readers' processing of foreignised elements in translated South African picturebooks. Target, 25(2), 180-227. doi:10.1075/target.25.2.03kru

Kruger, H., \& Kruger, J.-L. (2017). Cognition and reception. In J. W. Schwieter \& A. Ferreira (Eds.), The handbook of translation and cognition (pp. 71-89). Hoboken, NJ: John Wiley \& Sons.

Kruger, J.-L., Doherty, S., Fox, W., \& de Lissa, P. (2018). Multimodal measurement of cognitive load during subtitle processing: Same-language subtitles for foreign language viewers. In I. Lacruz \& R. Jääskeläinen (Eds.), Innovation and expansion in translation process research (pp. 267-294). Amsterdam: John Benjamins.

Kruger, J.-L., Sanfel, M. T. S., Doherty, S., \& Ibrahim, R. (2016). Towards a cognitive audiovisual translatology: Subtitles and embodied cognition. In R. M. Martín (Ed.), Reembedding translation process research (pp. 171-193). Amsterdam: John Benjamins.

Künzli, A., \& Ehrensberger-Dow, M. (2011). Innovative subtitling: A reception study. In C. Alvstad, A. Hild, \& E. Tiselius (Eds.), Methods and Strategies of Process Research: Integrative Approaches in Translation Studies (pp. 187-200). Amsterdam/Philadelphia: John Benjamins.

McEwan, I. (2005, September 20). Hello, would you like a free book? The Guardian. Retrieved from https://www.theguardian.com/books/2005/sep/20/ficti on.features 11

Mehdizadkhani, M., \& Khoshsaligheh, M. (2019). Insertion or voice-off in rendition of graphic codes: An experiment in Persian dubbing. Visual Communication. doi: $10.1177 / 1470357219838599$

Moshtaqmehr, R. (2000). Talaqqi-ye ghodama az tarjomeh-ye adabi [The attitude of the ancients about literary translation]. Zaban va Adabiyat, 11, 103-112.

Naji-Nasrabadi, M. (2001). Seyr-e Tarjome dar Iran va Moa'refi-ye Ketab (Fehrest-e Ketabha-ye Farsi Shodeh Chapi) [The development of translation in Iran and introducing a book (catalogue of printed books translated into Persian)]. Ayine-ye Pajuhesh, 12(2),70-79.

Newmark, P. (1981). Approaches to translation. Oxford, England: Pergamon.

Nida, E. A. (1964). Toward a science of translation. Leiden, The Netherlands: E.J. Brill.

Nord, C. (2000). What do we know about the target-text receiver? In A. Beeby, D. Ensinger, \& M. Presas (Eds.), Investigating translation: Selected papers from the 4th international congress on translation (pp. 195-212). Amsterdam: John Benjamins.

Pitkäsalo, E.(2018). Images without words - the focus group as a method of examining the reading experience of comics. Linguistica Antverpiensia, New Series: Themes in Translation Studies, 17, 231-245. 
Puurtinen, T. (1994). Dynamic style as a parameter of acceptability in translated children's books. In M. Snell-Hornby, F. Pöchhacker, \& K. Kaindl (Eds.), Translation studies: An interdiscipline: Selected papers from the Translation Studies Congress, Vienna, 1992 (pp. 83-90). Amsterdam: John Benjamins.

Pym, A. (2014). Exploring translation theories. London, England: Routledge.

Risku, H., Pichler, T., \& Wieser, V. (2017). Transcreation as a translation service: Process requirements and client expectations. Across Languages and Cultures, 18(1), 53-77. doi:10.1556/084.2017.18.1.3

Saldanha, G., \& O’Brien, S. (2013). Research methodologies in translation studies. Manchester, England: St. Jerome.

Schumacker RE., \& Lomax, RG. (2004). A beginner's guide to structural equation modeling. Mahwah, NJ: Lawrence Erlbaum Associates.

Sousa, C. (2002). TL versus SL implied reader: Assessing receptivity when translating children's literature. Meta, 47(1), 16-29. doi:10.7202/007988ar

Suojanen, T., Koskinen, K., \& Tuominen, T. (2015). User-centered translation. Abingdon, England: Routledge.

Ullman, J. B. (2001). Structural equation modeling. In: BG. Tabachnick BG, \& LS. Fidell (Eds.), Using multivariate statistics (4th ed.) (pp. 653-771). Needham Heights, MA: Allyn \& Bacon.

Venuti, L. (1998). The scandals of translation: Towards an ethics of difference. London, England: Routledge.

Walker, C. (2019). A cognitive perspective on equivalent effect: using eye tracking to measure equivalence in source text and target text cognitive effects on readers. Perspectives, 27(1), 124-143. doi:10.1080/0907676X.2018.1449870

Wang, F., \& Humblé, P. (in press). Readers' perceptions of Anthony Yu's selfretranslation of The Journey to the West. Perspectives, 1-21. doi:10.1080/0907676X.2019.1594317

Wolf, M., \& Fukari, A. (Eds.). (2007). Constructing a sociology of translation. Amsterdam: John Benjamins.

Yankelovich, S., \& White, I. 1978. Consumer research study on reading and book purchasing. Book Industry Study Group. 


\section{Appendix A - The Fiction Translation Expectancy Norms Scale}

This research investigates the expectations of Iranian readers regarding the features of a favourably received fiction translation (novel, novella, short story, etc.) into Persian. You have been selected because of your self-report that you read at least 3 translated fiction books a year and you speak Persian as your mother tongue. Please rate the importance of the following statements from 1 to 5 (1: Not important at all; 2: Of little importance; 3: No opinion; 4: Important; 5: Very important).

Gender:

Highest completed level of education:

Main items

01 Placing importance on the fidelity principle in retaining the style of the ST

02 Foregrounding the aesthetic features of the text for the enjoyment of readers

03 Highlighting the differences between source and target cultures

04 Consistency in the writing style of the TT

05 Retaining the cover design of the ST

06 Helping the readers immerse in the story

07 Including translator's preface

08 Avoiding word-for-word translation

09 Using a literary language in the TT

10 Entirely accurate translation of the ST

11 Translating the works of well-known international authors

12 Promoting Persian language

13 Disambiguating the ST

14 Prioritizing faithfulness over fluency

15 Retaining the author's tone

16 Using a clear and rational language in the TT

17 Fulfilling the purpose defined for the translated text

18 Meeting the needs of the target culture

19 Rewriting the ST based on the presupposed background knowledge of the readers

20 Creating a picture of the story world in the preface

21 Explaining the choice of ST for translation in preface

22 Describing the difficulties of translating the text in the preface

23 Expressing the main characteristics of the story in the preface

24 Including a translation of the author's preface

25 Retaining the distinguished features of the source culture represented in the ST

26 Effective visualization of the events of the story

27 Giving due consideration to the correct usage of Persian grammar

28 Literal translation of the sensitive/important parts of the ST

29 Transmitting the real spirit of the ST to the target reader

30 Transferring the names of cultural ceremonies, foods, and customs of ST to TT without any change

31 Providing explanations for the cultural ceremonies, foods, and customs of the source culture in the footnotes

32 Distancing from the writing style of textbooks

33 Including the synopsis of the story in the preface

34 Footnoting the original names of characters and places

35 Providing a brief biography of the author in the preface

36 Discussing the author's intellectual perspectives in the preface

37 Keeping the author's style unless for a solid reason

38 Providing explanations for unfamiliar culture-bound elements in the footnotes

39 Using pure Persian words

40 Keeping the preface as short as possible

41 Lexical diversity in the TT

42 Increasing the clarity of the text by providing pictures

43 Providing a clear definition of faithfulness in the preface

44 Keeping the sentences as short as possible

45 Ensuring that the TT reads fluently

46 Having concern for the learning of readers

47 Maintaining the level of complexity of ST language

48 Providing the Persian equivalent of foreign proverbs/expressions in the text and their word-for-word translation in the footnotes 